\title{
A010 GROUND-TRUTHING AIRBORNE EM - HYDROCHEMICAL CHARACTERIZATION OF A COAL MINE PLUME
}

D. BEAMISH, B.A. KLINCK AND J. TRICK

British Geological Survey, Keyworth, Nottingham, NG12 5GG, UK

Near Surface 2004 - 10th European Meeting of Environmental and Engineering Geophysics, Utrecht, The Netherlands. 06 September. Session: Pollution Detection and Remediation Monitoring

\begin{abstract}
A trial airborne EM (AEM) survey was carried out across a 13 x $9 \mathrm{~km}$ area of the northern Nottinghamshire (UK) coalfield. One of the objectives was to examine the influence of collieries situated above the Triassic Sherwood Sandstone aquifer. The conductivity models obtained from the AEM survey revealed extensive zones of enhanced subsurface conductivity in the vicinity of all the collieries in the survey area. The purpose of the present study is to provide information regarding subsequent investigations (ground geophysics and borehole) to confirm the AEM results and to investigate the geochemical nature of the conductive zone identified in the vicinity of one of the collieries.
\end{abstract}

\section{The airborne EM survey}

The fixed wing airborne EM system developed by the Geological Survey of Finland (GTK) used in the surveys is described in detail by Poikonen et al (1998). The coils are wing-tip mounted (separation of $21.4 \mathrm{~m}$ ) and are vertical coplanar. Coupling ratios at two frequencies (3 and $14 \mathrm{kHz}$ ) are recorded simultaneously at $4 \mathrm{~Hz}$. Sampling along the flight direction is typically between 10 and $15 \mathrm{~m}$.

The coalfield test area (13 x $9 \mathrm{~km})$ was flown entirely at low level (40 m) and regional coverage was obtained using $200 \mathrm{~m}$ flight lines, together with two infill zones incorporating 50 $\mathrm{m}$ flight lines. The geology of the area is relatively uniform and comprises a thick (typically $>100 \mathrm{~m}$ ) Triassic unit (the Sherwood Sandstone). The measured real and imaginary coupling ratios at each frequency are converted to apparent conductivity using stable procedures. These simple methods provide 1D mapping of the conductivity variations. The variation of the information with frequency is used as a surrogate for depth control.

According to background studies within the area, a cut-off level of about $20 \mathrm{mS} / \mathrm{m}$ should identify anthropogenic sources of enhanced conductivities. The regional results indicate that highly conductive features (> $100 \mathrm{mS} / \mathrm{m}$ ) occur in association with all of the colliery spoil areas including the former pits of Clipstone, Langwith, Shirebrooke, Warsop Vale as well as the active pits of Thoresby and Welbeck. Away from the immediate vicinity of the spoil zones, less conductive anomalies with a plume-like geometry are observed.

The zone around Thoresby colliery was selected for further ground-based studies. The area was overflown with 'in-fill' flight lines thus providing an E-W flight line separation of $50 \mathrm{~m}$. The eastern-most area, shown here, lies outside the mine perimeter. Figure 1 shows the AEM conductivity results obtained at high frequency ( $14 \mathrm{kHz}$ ) and low frequency ( $3 \mathrm{kHz}$ ) to the east of the mine. Conductivity values are contoured between a low value of $20 \mathrm{mS} / \mathrm{m}$ (blue 
line) and $70 \mathrm{mS} / \mathrm{m}$ (magenta line). It can be seen that the lower frequency results (Fig. 1b) indicate a more extensive high conductivity anomaly $(>70 \mathrm{mS} / \mathrm{m})$, shown with crosshatch infill. This area contains the locations of 4 ground-based Vertical Electric Soundings (VES, star symbols) together with the 3 boreholes locations (red symbols) drilled to provide a hydrochemical characterization of the AEM plume.
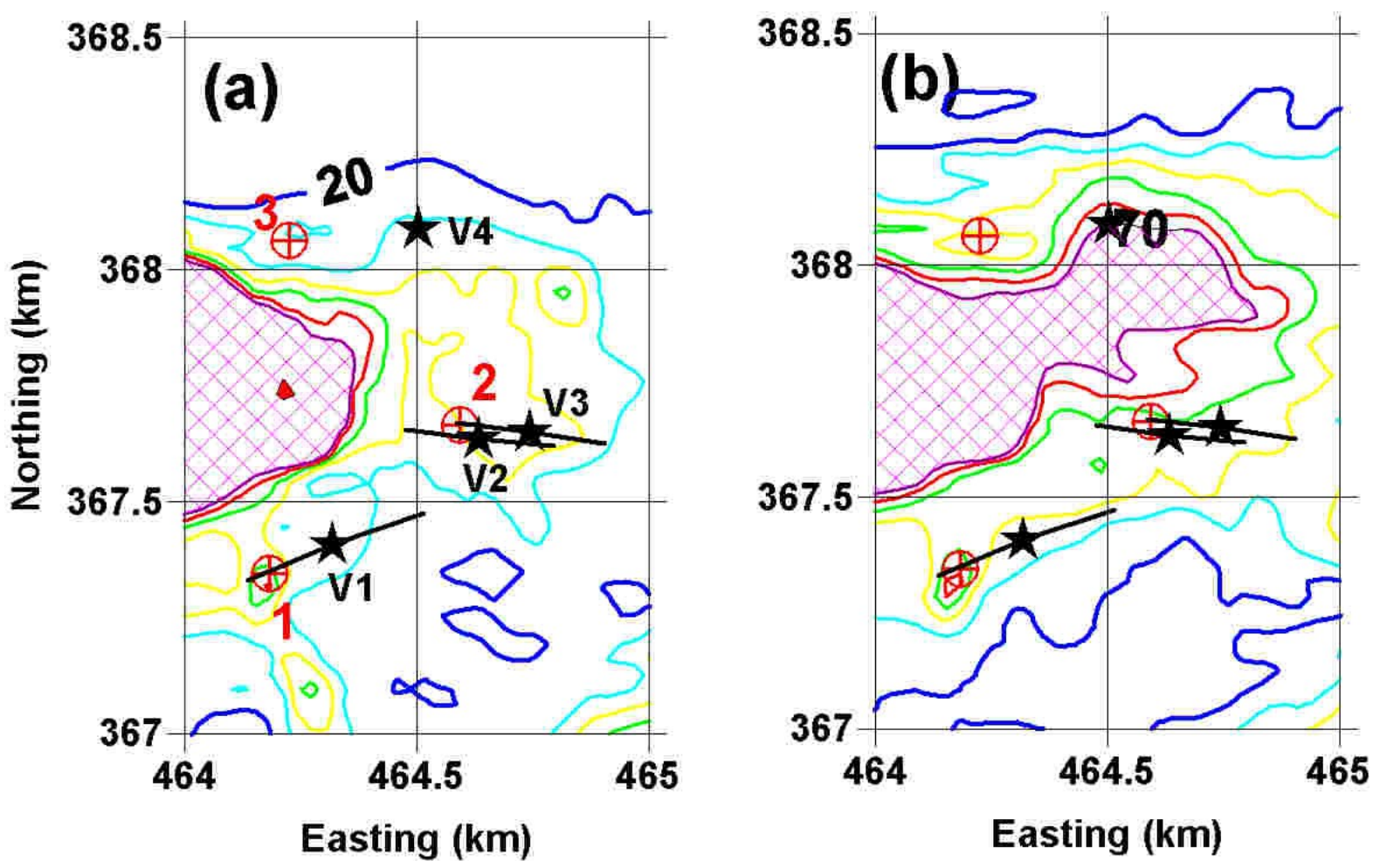

Figure 1. Half-space apparent conductivity maps obtained over a $1 \mathrm{x} 1.5 \mathrm{~km}$ area to the east of Thoresby colliery (a) $14 \mathrm{kHz}$ and (b) $3 \mathrm{kHz}$. Conductivity values are contoured in the interval 20 to $70 \mathrm{mS} / \mathrm{m}$, crosshatch denotes values $>70 \mathrm{mS} / \mathrm{m}$. Red symbols are borehole locations; black star symbols denote VES sounding centers.

\section{VES soundings}

A series of Schlumberger VES soundings have been made across the survey area to confirm the AEM results. These soundings provide a greater level of depth discrimination than the models that can be obtained from the AEM data alone. Ground truthing of AEM survey data using TDEM soundings has previously been described by Fitterman and Deszcz-Pan (1998). The four soundings to the east of the mine all confirmed that enhanced conductivities were present and that they were likely to be within the aquifer (precise local water table depths were not known). Figure 2a shows a set of 1D conductivity models obtained from VES2. The maximum $\mathrm{AB} / 2$ distance is $160 \mathrm{~m}$ and the distance from the sounding centre to $\mathrm{BH} 2$ is $51 \mathrm{~m}$. The three models are used to emphasize the inherent issues of model equivalence. A conventional (four layer) model is shown with infill. The main conductivity increase is observed at a depth of $13 \mathrm{mbgl}$. This depth corresponds to that of the water table observed in the nearest borehole (BH2). The other two models, shown with coloured lines, are obtained from regularized (minimum structure Occam) procedures using logarithmic depth to mimic decreasing resolution. The blue model uses 19 layers (0 to $100 \mathrm{~m}$ ) and the red model consists of 95 layers. All 3 models are equivalent in terms of misfit. The 3 other VES soundings shown in Figure 1 display a similar behavior to that of VES2.

\section{Borehole information}

The 3 borehole sites were selected to provide information on hydraulic gradient and to recover core for pore water extraction and geochemical analysis. It should be noted that the 
boreholes are not located on the highest conductivity zone observed in the lower frequency AEM results (Fig. 2b). The boreholes were drilled using rotary-cored air flush to depths of about $55 \mathrm{~m}$. A suite of borehole geophysical logs was obtained including gamma, resistivity, induction, temperature and fluid electrical conductivity (EC25).

The induction tool, measuring formation conductivity, was equivalent to the Geonics EM39. Correlations between borehole conductivity logs and AEM conductivity models have been studied in relation to saline conditions in Australian catchment management programs (e.g. Lane et al., 2001). The tool has a low conductivity limit of $5 \mathrm{mS} / \mathrm{m}$ and cannot measure the near surface, unsaturated sandstone values. The conductivity log is shown in Figure 2b. It is evident that below the water table, conductivity ascends to values of $>30 \mathrm{mS} / \mathrm{m}$ by a depth of $22 \mathrm{~m}$ and high conductivities are then maintained throughout the water column. The conductivity log appears as a hybrid of the three types of VES model shown in Figure 2a. Borehole formation conductivities reach maximum values of 25 mS/m, (BH1, $39 \mathrm{~m}$ ), 53 $\mathrm{mS} / \mathrm{m}$ (BH2, $46 \mathrm{~m}$ ) and $37 \mathrm{mS} / \mathrm{m}$ (BH3, $34 \mathrm{~m}$ ). Maximum fluid conductivities (EC25) are 1770 (BH1), 3619 (BH2) and $1450 \mathrm{uS} / \mathrm{cm}$ (BH3). The plume is characterized by being net alkaline.

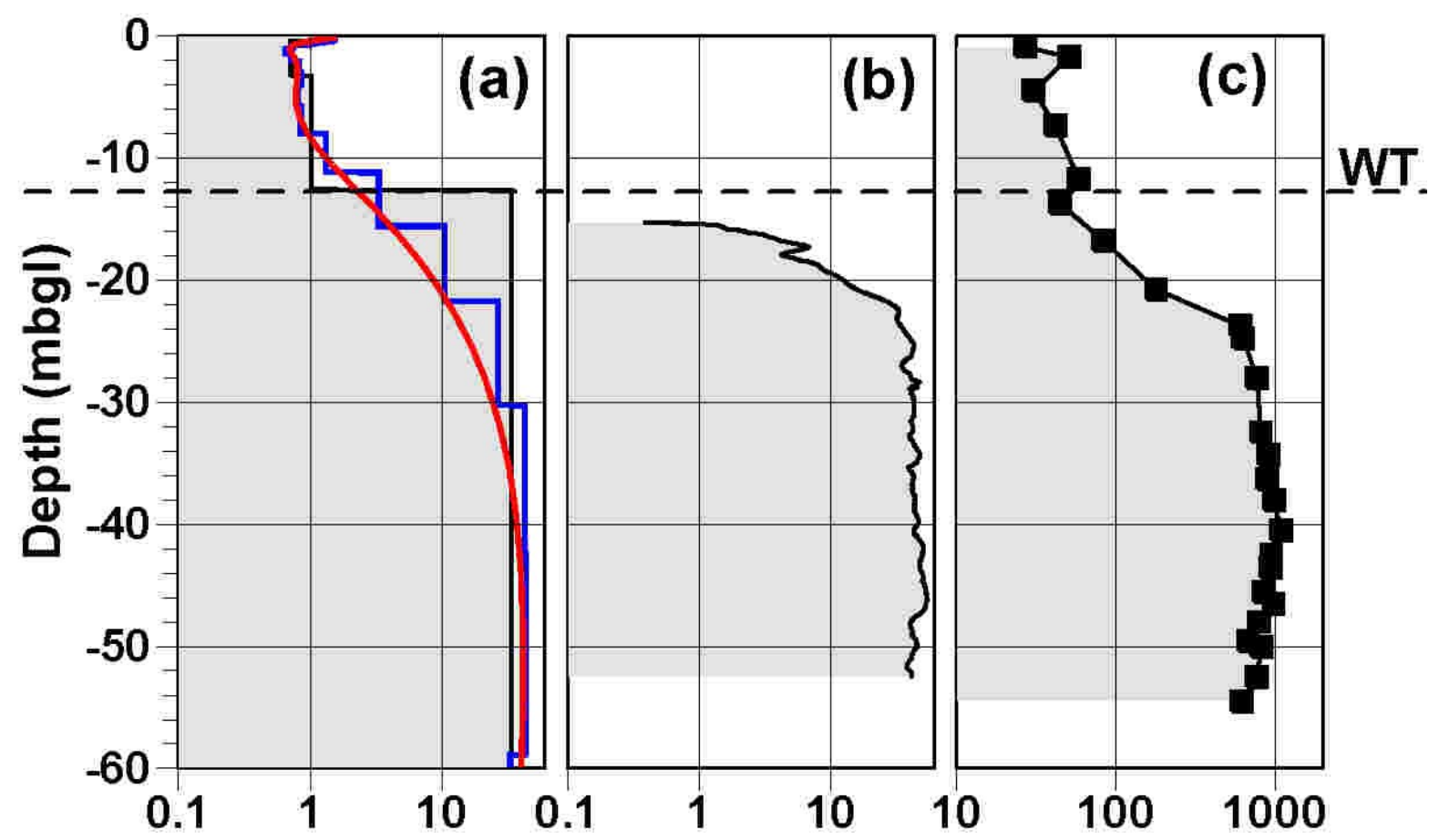

Figure 2. Results in the vicinity of BH2. (a) 3 1D conductivity models obtained from VES2 (4, 19 and 95 layers), units of $\mathrm{mS} / \mathrm{m}$. (b) Downhole induction conductivity log, units of $\mathrm{mS} / \mathrm{m}$. (c) Pore water core chloride content, units of mg/l. WT denotes water table in BH2.

\section{Plume hydrochemistry}

Sections of core were selected for pore water extraction. Core selection was based on features within the induction logs. Three further water samples (borehole, storm tank and settlement pond) were obtained from Thoresby Colliery to obtain source term chemistry. The water samples derive from the mine borehole and are used in dust suppression and coal washing. The main feature of the storm tank effluent is high potassium (82 mg/l) and high chloride (> $12000 \mathrm{mg} / \mathrm{l})$.

The chemical profiles for all 3 boreholes indicate that chloride mirrors the behavior of formation conductivity most closely and is the major contributor to TDS. The pore water chloride profile is shown in Figure 2c using a logarithmic scale. The onset of the chloride 
increase appears to be associated with the water table however a high concentration ( $>500$ $\mathrm{mg} / \mathrm{l})$ is only established at a depth of $24 \mathrm{~m}$. The other major contributor to TDS is sulphate. Maximum chloride concentrations (and depths) in the 3 boreholes are BH1: $448 \mathrm{mg} / \mathrm{l}$ (22.5 m), BH2: $1083 \mathrm{mg} / \mathrm{l}(40.5 \mathrm{~m})$ and BH3: $857 \mathrm{mg} / \mathrm{l}$ (33 m). Backgound values of chloride in the area are typically $<100 \mathrm{mg} / \mathrm{l}$. Overall, the variations between boreholes reflect the behavior observed in the AEM conductivity variations shown in Figure 1.

As well as the high chloride a number of other chemical parameters indicate a colliery spoil leachate source for the dissolved plume in particular barium, potassium and sulphate. The latter two ions occur at concentrations in excess of background. There is strong supporting evidence that the groundwater in the boreholes is a mixture of a colliery spoil type and typical Sherwood Sandstone groundwater. The Thoresby Colliery production borehole tends to fall within the field of the pore waters indicating some impact from the colliery due to increased chloride and sulphate.

The anions chloride and bromide are generally considered to behave conservatively, i.e. they do not undergo attenuation processes in the aquifer matrix. Since the only effect of the aquifer flow on the colliery leachate is dilution, the ratio of chloride to bromide should remain constant. The chloride/bromide ratio profile has been obtained for each of the boreholes. A value of 100 corresponds to the two process waters analysed from the site. A similar constant value is found within the conductive plume at all 3 boreholes. It is concluded that a clear geochemical association between the AEM conductive plume and the colliery has been established.

\section{Conclusions}

AEM models identified high conductivity sources associated with all colliery zones in a trial survey. Lower conductivity plumes appeared to emanate from the source areas. VES soundings confirmed that the main AEM conductive zones are associated with aquifer depths. Three boreholes were drilled into the geophysical anomaly. The three, cored boreholes have confirmed that there is a groundwater plume with high concentrations of total dissolved solids, compared to background, moving east from the Thoresby Colliery on a hydraulic gradient of 0.023 . Analysis of the porewaters indicates that their chemistry could result from the mixing of a typical Sherwood Sandstone composition with colliery spoil leachate. The AEM conductivity models have been successfully correlated with VES models, borehole induction logs, total dissolved solids and chloride in the pore waters.

\section{References}

Fitterman, D. and Deszcz-Pan, M., 1998. Helicopter EM mapping of saltwater intrusion in Everglades National Park, Florida. Exploration Geophysics. 29, 240-243.

Lane, R., Heislers, D. and McDonald, P., 2001. Filling in the gaps - validation and integration of airborne EM data with surface and subsurface observations for catchment management - an example from Bendigo, Victoria, Australia. Exploration Geophysics. 32, 225-235.

Poikonen, A., Sulkanen, K, Oksama, M., Suppala, I., 1998. Novel dual frequency fixed wing airborne EM system of Geological Survey of Finland (GTK). Exploration Geophysics 29, 4651 . 